\title{
A CLINICAL STUDY OF LIPID ABNORMALITIES AND ANGIOGRAPHIC PROFILE IN PATIENTS OF CORONARY ARTERY DISEASE ON STATINS UNDERGOING CORONARY ANGIOGRAPHY
}

\author{
Raghu Kishore Galla, Ch.Susmitha, G.Indrani.
}

\begin{abstract}
Background: The traditional risk factors of coronary artery disease (CAD) are Age, Genetic factors, Smoking, Hypertension, Diabetes and Dyslipidemia occurrence of each of which influence the presentations of the disease and its severity of the angiographic profile. With changing scenario of risk factor assessment due to global increase in CAD and starting the statins quite early for patients with risk factors without the CAD, we want to see the present status of lipids in patients undergoing coronary angiogram (CAG).

Objective: We aim to evaluate the occurrence of various risk factors especially lipid abnormalities and correlate them with angiographic severity in patients presenting with CAD and undergoing $C A G$

Methods: We evaluated 504 consecutive patients already on statins presenting with $C A D$ and undergoing coronary angiogram between august 2015 to December 2016 at our center. We obtained the detailed clinical, biochemical and angiographic profile from the records and analyzed the occurrence of risk factors and correlated the lipid abnormalities and angiographic profile for any statistical significance using Minitab 17 software.

Results: Of the total 504 patients 331 (65.6\%) were males. 347 (68.8\%) had Hypertension, 258 (51.1\%) had DM, 370 (73.4\%) had Dyslipidemia and 128 (25.3\%) had LV dysfunction.303 (60.1\%) had abnormal coronary angiograms. Of these 148 (48.8\%) had single vessel disease (SVD), 85 (28\%) had double vessel disease (DVD), 70 (23.2\%) had triple vessel disease (TVD).Abnormal CAG is significantly found in Males ( $p=$ 0.03), Hypertension $(p=0.00), D M(P=0.01)$ and $L V$ dysfunction $(p=0.00)$. Dyslipidemia had tendency for correlation with abnormal CAG but not statistically significant $(p=0.07)$. The levels of LDL, HDL and triglycerides didn't correlate with the angiographic abnormality. In patients with severe CAD i.e. TVD the determinants are age $(p=0.01)$, male sex $(p=0.01)$, smoking $(p=0.02), H T N(p=$ 0.002), DM ( $p=0.03)$, LV dysfunction $(p=0.006)$. Neither
\end{abstract}

Article received on 23 APR 2017, published on 30 APR 2017.

Raghu Kishore Galla ${ }^{1}$ Ch.Susmitha ${ }^{2}$, G.Indrani ${ }^{3}$.

${ }^{1}$ DM Resident, Department of Cardiology, NIMS, India

${ }^{2}$ DM Resident, Department of Nephrology, NIMS, India

${ }^{3} \mathrm{Ph}$. D Student, Department of Cardiology, NIMS, India

Corresponding author: Raghu Kishore Galla

Email: raghukishoregalla@gmail.com
Dyslipidemia ( $p=0.2$ ) nor levels of Total cholesterol, HDL, $L D L, T G$ determined the occurrence of TVD. Occurrence of DVD correlated significantly with age $(p=0.001)$, male gender $(p=0.002)$ and LV dysfunction ( $p=0.02)$.In SVD Male gender ( $p$ $=0.003), \operatorname{HTN}(p=0.001), L V$ dysfunction $(p=0.00), T G(p=$ 0.03) had showed significant correlation. Occurrence of Dyslipidemia didn't show any correlation with the occurrence of SVD $(p=0.26)$ or DVD $(p=0.43)$.High levels of individual lipid components except TG in SVD didn't show any correlation in occurrence of DVD or SVD.

Conclusion: In patients presenting with CAD on statins with abnormal CAG, age, male gender, HTN, DM and LV dysfunction of any severity are the determinants but not the occurrence of Dyslipidemia or the levels of Total cholesterol of LDL, HDL or TG. The occurrence of Dyslipidemia or levels of individual lipid component abnormalities except for high levels of TG in SVD didn't show any significant correlation with the occurrence of SVD, DVD or TVD.

Keywords: Dyslipidemia, Coronary Artery Disease

\section{INTRODUCTION:}

The traditional risk factors for Coronary artery disease (CAD) are age, genetic factors, smoking, hypertension (HTN), diabetes (DM) and dyslipidemia. The occurrence of each of these risk factors may influence the presentation of the disease and severity of the angiographic profile. Dyslipidemia including high LDL cholesterol and low HDL is one of the most commonly associated and frequently addressed risk factors of present CAD. Use of the statins to control dyslipidemia is an important component of today's therapy in patients presenting with or having risk factors for CAD. Benefit of statins in secondary prevention of the cardiovascular disease is proved beyond doubt in many clinical trials. But the use of statins in the primary prevention of cardiovascular disease in asymptomatic patients is less well established[1]. At least five authoritative guidelines, including the recent publication from the US Preventive Services Task Force addressed this issue[2-7]. Their differing recommendations, however, suggest considerable uncertainty in the underlying data, creating 
confusion for both clinicians and patients. With the changing scenario of risk factor assessment due to global increase in cardiovascular disease and there is a trend towards the use of statins quite early in asymptomatic people with risk factors but without the established CAD. There may be a change in disease profile of CAD in patients taking statins early in the course of the disease, severity of which may correlate with the control of various lipid components.

The aim of the present study is to evaluate the present status of the lipids and their correlation with the angiographic profile of the patients presenting with stable CAD or acute coronary syndromes (ACS) undergoing coronary angiography (CAG) who is already taking statins either for secondary or primary prevention.

\section{MATERIALS \& METHODS:}

We have retrospectively analyzed the data of 504 patients who are already using statins either for primary or secondary prevention of cardiovascular disease presenting with symptoms of CAD and undergoing CAG in the Nizam's Institute of Medical Sciences, Hyderabad, India between August 2015 to December 2016. We included both chronic stable angina (CSA) or acute coronary syndrome (ACS) i.e. unstable angina (UA), myocardial infarction (STEMI/NSTEMI) patients in our study. We excluded patients with significant renal, hepatic \& other systemic dysfunction and patients who are in severe cardiogenic shock.

Institutional ethical guidelines were followed. Informed consent was taken from all the patients before inclusion into the study. All patients were evaluated after a detailed history, physical examination, and biochemical investigations including fasting lipid profile. Demographic and clinical characteristics of patients were documented.

All patients were pre-treated with oral sedation and antihistamine before CAG. It was done through either radial or femoral route. All the patients were classified according to their angiographic profile as single vessel disease (SVD) i.e. $>70 \%$ stenosis involving one epicardial coronary artery or double vessel disease (DVD) i.e. $>70 \%$ stenosis in 2 epicardial coronary arteries or triple vessel disease (TVD) i.e. $>70 \%$ stenosis of 3 epicardial coronaries or 2 epicardial coronaries $+>$ $50 \%$ stenosis of the left main coronary artery (LMCA).
Patients have monitored for any route related complications like hematoma or bleeding for $24 \mathrm{hrs}$. ECGs or cardiac enzymes were performed in patients complaining of chest pain after the procedure. They were discharged after 24 hours in a stable condition if CAG is normal or shows mild disease. Patients having significantly abnormal CAGs are planned for early revascularization either with percutaneous coronary intervention (PCI) or coronary artery bypass grafting (CABG).

These patients are divided into two subgroups depending on whether having dyslipidemia or not. Dyslipidemia in patients who are on statins is defined as patients having one or more of the following i.e. Total cholesterol $(\mathrm{TC})>200 \mathrm{mg} / \mathrm{dl}$, LDL cholesterol $(\mathrm{LDL})>$ $130 \mathrm{mg} / \mathrm{dl}$, Triglycerides (TG) > $150 \mathrm{mg} / \mathrm{dl}$, HDL cholesterol (HDL) $<40 \mathrm{mg} / \mathrm{dl}$ in males and $<50 \mathrm{mg} / \mathrm{dl}$ in females. Most of the baseline demography, risk factors, biochemical variables, clinical and angiographic profiles and complications were compared between these.

\section{Statistical Analysis:}

Data analysis was performed using Minitab version 17 software. The frequency of abnormal results was determined for each marker and compared by the Fisher's exact test. Continuous variables were expressed as mean $\pm \mathrm{SD}$ and were compared by the ANOVA test. Multiple regression analysis was performed to test the significance between two subgroups of normal Vs abnormal CAG for different variables including dyslipidemia, individual lipid components and nonlipid variables with occurrence of SVD, DVD or TVD. Categorical variables were compared using chi-square test. Results with a ' $\mathrm{p}$ ' value $<0.05$ are considered to be significant.

\section{RESULTS:}

Totally 504 patients presenting with CAD undergoing CAG between August 2015 to December 2016 were included in the study. Of the total 504 patients, 331 $(65.6 \%)$ were males. Average age at presentation is 56.50 \pm 11.25 years. Of them 347 (68.8\%) had Hypertension, 258 (51.1\%) had DM, 370 (73.4\%) had Dyslipidemia and $104(20.6 \%)$ are smokers. $425(84.3 \%)$ presented with CSA and 79 (15.6\%) with ACS. 128 (25.3\%) patients had $\mathrm{LV}$ dysfunction. Mean hemoglobin is $12.78 \pm 1.95 \mathrm{gm} / \mathrm{dL}$. 
Baseline demographic characteristics of the patients are depicted in Table 1.

Table 1: Baseline Demographic Characteristics

\begin{tabular}{|l|l|}
\hline \multicolumn{1}{|c|}{ Parameter } & \multicolumn{1}{c|}{ Value } \\
\hline Age & $56.50 \pm 11.25$ \\
\hline Males & $331(65.6 \%)$ \\
\hline Hypertension & $347(68.8 \%)$ \\
\hline Diabetes & $258(51.1 \%)$ \\
\hline Smoking & $104(20.6 \%)$ \\
\hline CSA & $425(84.3 \%)$ \\
\hline ACS & $79(15.6 \%)$ \\
\hline LV dysfunction & $128(25.3 \%)$ \\
\hline Hemoglobin & $12.78 \pm 1.95$ \\
\hline Dyslipidemia & $370(73.4 \%)$ \\
\hline TC $(\mathrm{mg} / \mathrm{dl})$ & $147.16 \pm 93.72$ \\
\hline LDL $(\mathrm{mg} / \mathrm{dl})$ & $76.89 \pm 39.40$ \\
\hline TG $(\mathrm{mg} / \mathrm{dl})$ & $133.88 \pm 61.60$ \\
\hline HDL $(\mathrm{mg} / \mathrm{dl})$ & $42.23 \pm 16.60$ \\
\hline
\end{tabular}

Of the total patients $303(60.1 \%)$ had abnormal coronary angiograms. Of these $148(48.8 \%)$ had single vessel disease (SVD), 85 (28\%) had double vessel disease (DVD), 70 (23.2\%) had triple vessel disease (TVD). Basic angiographic profile of the patients is depicted in Table 2.

Table 2: Basic Angiographic Profile

\begin{tabular}{|l|l|}
\hline \multicolumn{1}{|c|}{ CAG } & \multicolumn{1}{c|}{ n = 504 } \\
\hline Normal & $201(39.8 \%)$ \\
\hline SVD & $148(29.3 \%)$ \\
\hline DVD & $85(16.9 \%)$ \\
\hline TVD & $70(13.9 \%)$ \\
\hline
\end{tabular}

Binary logistic regression analysis correlating the abnormal CAG with various patient characteristics showed that abnormal CAG is significantly found in Males $(p=0.03)$, Hypertension $(p=0.00), D M(p=0.01)$ and LV dysfunction $(p=0.00)$. Dyslipidemia had a tendency for correlation with abnormal CAG but not statistically significant $(p=0.07)$. The levels of TC, LDL, HDL and triglycerides didn't correlate with the angiographic abnormality (Table .3).
Table 3: $p$ Value correlating the abnormal CAG

\begin{tabular}{|l|l|}
\hline Variable & p Value \\
\hline Age & 0.15 \\
\hline Male sex & 0.003 \\
\hline HTN & 0.00 \\
\hline DM & 0.011 \\
\hline Smoking & 0.62 \\
\hline LV dysfunction & 0.00 \\
\hline Dyslipidemia & 0.07 \\
\hline ACS/CSA & 0.15 \\
\hline TC $(\mathrm{mg} / \mathrm{dl})$ & 0.24 \\
\hline LDL (mg/dl) & 0.27 \\
\hline HDL (mg/dl) & 0.32 \\
\hline TG (mg/dl) & 0.84 \\
\hline Hemoglobin $(\mathrm{gm} / \mathrm{dl})$ & 0.72 \\
\hline
\end{tabular}

In the patients having dyslipidemia there is no significant difference from patients not having dyslipidemia in occurrence of abnormal CAG $(\mathrm{p}=0.5)$ or its severity in form of SVD $(p=0.32)$, DVD $(p=0.78)$ and TVD $(p=0.88)($ Table 4$)$.

Table 4: CAG in Dyslipidemia+ vs No Dyslipidemia

\begin{tabular}{|l|l|l|l|}
\hline \multicolumn{1}{|c|}{ CAG } & Dyslipidemia+ & $\begin{array}{c}\text { No } \\
\text { Dyslipidemia }\end{array}$ & $\begin{array}{c}\mathbf{p} \\
\text { Value }\end{array}$ \\
\hline $\begin{array}{l}\text { Normal } \\
\text { Coronaries }\end{array}$ & $151(40.8 \%)$ & $50(37.3 \%)$ & 0.537 \\
\hline SVD & $104(28.1 \%)$ & $44(32.8 \%)$ & 0.320 \\
\hline DVD & $64(17.2 \%)$ & $21(15.6 \%)$ & 0.788 \\
\hline TVD & $51(13.7 \%)$ & $19(14.1 \%)$ & 0.885 \\
\hline
\end{tabular}

Using Multiple logistic regression analysis we have compared the occurrence of various risk factors including dyslipidemia along with individual lipid components and other important characteristics in patients with normal CAGs Vs those who are having different severities of CAD in the form of SVD, DVD or TVD. In patients with severe CAD i.e. TVD the determinants are age $(p=0.01)$, Male sex $(p=0.01)$, smoking $(p=0.02)$, HTN $(p=0.002)$, DM $(p=0.03), L V$ dysfunction $(p=0.006)$. Neither Dyslipidemia $(p=0.2)$ nor levels of Total cholesterol, HDL, LDL, TG determined the occurrence of TVD.

Occurrence of DVD correlated significantly with age ( $p$ $0.001)$ male gender $(p=0.002)$ and LV dysfunction $(p=$ $0.02)$. Neither dyslipidemia $(p=0.43)$ nor the individual 
lipid components had showed significant correlation. HTN $(\mathrm{p}=0.069)$ and DM $(\mathrm{p}=0.074)$ have tendency for correlation with occurrence of DVD but not statistically significant.

In SVD, male gender $(p=0.03), \operatorname{HTN}(p=0.01), \mathrm{LV}$ dysfunction $(\mathrm{p}=0.00)$ had showed significant correlation. High levels of TG showed significant correlation with the occurrence of SVD with $\mathrm{p}$ value of 0.03. Occurrence of Dyslipidemia $(p=0.2)$ and other lipid component have not shown any correlation with the occurrence of SVD.

Multiple logistic regression analysis and $p$ values for different variables in normal Vs abnormal CAGs depicted in Table 5.

Table 5: $\mathrm{p}$ values for different variables in normal Vs abnormal CAGs

\begin{tabular}{|l|l|l|l|}
\hline Variable & SVD & DVD & TVD \\
\hline Age $($ Yrs $)$ & 0.07 & 0.001 & 0.01 \\
\hline Male sex & 0.03 & 0.002 & 0.01 \\
\hline Smoking & 0.63 & 0.52 & 0.02 \\
\hline HTN & 0.01 & 0.069 & 0.002 \\
\hline DM & 0.89 & 0.074 & 0.03 \\
\hline LV dysfunction & 0.003 & 0.02 & 0.006 \\
\hline Dyslipidemia & 0.26 & 0.43 & 0.27 \\
\hline TC $(\mathrm{mg} / \mathrm{dl})$ & 0.17 & 0.71 & 0.99 \\
\hline LDL $(\mathrm{mg} / \mathrm{dl})$ & 0.77 & 0.78 & 0.54 \\
\hline TG $(\mathrm{mg} / \mathrm{dl})$ & 0.03 & 0.29 & 0.65 \\
\hline HDL $(\mathrm{mg} / \mathrm{dl})$ & 0.74 & 0.77 & 0.49 \\
\hline
\end{tabular}

\section{DISCUSSION:}

Use of statins has become part and parcel of routine cardiology practice in the treatment and prevention of the cardiovascular diseases (CVD) especially CAD. The benefits of statin therapy are attributed to pleiotropic effects that are independent of a lowering of the LDLcholesterol level. These effects include improved endothelial function [8], reduced vascular inflammation $[9,10,11]$ and reduced platelet adhesion and thrombosis [12].

The efficacy of the statins in the secondary prevention of the CVD is proved beyond doubt in number of well conducted randomized clinical trials (RCTs) including 4S (Scandinavian Simvastatin Survival Study ${ }^{13}$, HPS (Heart Protection Study) [13] , CARE (Cholesterol And Recurrent Events)[14], LIPID (Long- Term Intervention with Pravastatin in Ischaemic Disease) [15]. Thus use of statins became a standard therapy for the secondary prevention of cardiovascular events in patients with CVD and has a high risk of recurrent cardiovascular events.

In addition to start statin as early as possible, it was proved in many trials to titrate the dose of statins to the maximum to obtain best results in secondary prevention. According to (PROVE-IT [Pravastatin or Atorvastatin Evaluation and Infection Therapy][16], TNT [Treating to New Targets] [17], IDEAL [Incremental Decrease in Clinical Endpoints Through Aggressive Lipid Lowering])[18] the target dose for an individual patient should be selected as a dose close to or at the highest level the individual patient tolerates without side effects. Most of the standard guidelines advocate using of statins and titration to the maximum tolerated dose in secondary prevention of the CVD.

But the scenario was not same in all patients. Results of multiple randomized trials completed since 2005 do not support the notion that statin therapy has constant relative benefits across all risk groups, yet this assumption remains the fundamental justification for arguments to base therapy on absolute risk. The four important trials, CORONA (Controlled Rosuvastatin Multinational Trial in Heart Failure)[19], AURORA (A Study to Evaluate the Use of Rosuvastatin in Subjects on Regular Hemodialysis: An Assessment of Survival and Cardiovascular Events) [20], 4D (German Diabetes and Dialysis Study) [21], and GISSI-HF (Gruppo Italiano per lo Studio della Sopravvivenza nell' Insufficienza Cardiaca-Heart Failure) trials [22], in total included 13,613 patients and were reported between 2005 and 2009. All four of these well-conducted trials enrolled high-absolute-risk patients who achieved large low density lipoprotein (LDL) cholesterol reductions with statin therapy. Yet none showed significant clinical benefit in the secondary prevention of CVD.

Adding to the confusion created by these four trials some more important RCTs had shown significant benefit of using statins in primary prevention that are at very low risk of CVD. On the basis of high-quality randomized trial data, statin therapy can be considered as an adjunct to diet, exercise, and smoking cessation in the setting of primary prevention for those aged 50 and over with either diabetes (CARDS [Collaborative Atorvastatin Diabetes Study])[23], elevated LDL cholesterol (WOSCOPS [West of Scotland Coronary 
Prevention Study [24], MEGA) [25], low HDL cholesterol (AFCAPS)[26], or elevated hsCRP (JUPITER)[27]. These trials included 32,621 primary prevention patients and were published between 1998 and 2008, enrolled lowabsolute-risk patients, most of whom would not qualify for statin therapy under any current guideline issued in the United States or Europe. Yet each showed the marked benefit of statin therapy.

According to the accumulated data and most of the standard guidelines now the scenario has changed to start the statins as early as possible especially in the primary prevention of the CVD. Most of the physicians are starting statins at least in low dose as soon as the detection of risk factors before developing CVD. Most of the patients were started on statins for high TC, LDL or low HDL as a part primary prevention. Yet many of the patients present with CAD in whom it is very difficult to predict the lipids as a risk factor as most of them would already be regularly taking statins and have altered or suppressed levels of lipids. Only few of them are qualified to be called as having dyslipidemia. In this scenario, we want to study the effect of dyslipidemia in patients who are already on statins and presenting with CAD, undergoing CAG in our institution and correlating the severity of CAD with lipids and other risk factors.

We have enrolled 504 consecutive patients regularly taking statins presenting with stable or unstable CAD in the study undergo CAG in whom lipid parameters might have been altered by the time of presentation. We have correlated the angiographic profile with the occurrence of lipid and non-lipid risk factors and tested for any significance. In all previously mentioned primary and secondary prevention trials the primary and secondary endpoints were CV mortality and occurrence of recurrent $\mathrm{CV}$ events and none of the studies had correlated the angiographic severity of the CAD with the lipid levels. Two recent trials had addressed this issue and correlated the consequences of intensive lipid lowering with high dose statins on angiographic regression of the atheromatous plaque. Intensive lipid-lowering therapy with statins not only improves survival rates and clinical outcomes but also reduces the progression of atherosclerosis [28-31]. The recent REVERSal of Atherosclerosis with Lipitor (REVERSAL) study [29] showed that progression of the atheroma plaque volume was less with an aggressive dose of statin than with a moderate dose of statin.
Another study, the ASTEROID (A Study to Evaluate the Effect of Rosuvastatin on Intravascular Ultrasoundderived Coronary Atheroma Burden) trial [32], demonstrated that intensive statin therapy with $40 \mathrm{mg}$ Rosuvastatin daily could induce regression of coronary atherosclerosis. Furthermore, a very strong linear relationship was found between the LDL-cholesterol levels achieved and the course of atherosclerosis. But our study is not an interventional study and it is intended to see the correlation on dyslipidemia with the angiographic profile of the patients undergoing CAG.

Of the total 504 patients $331(65.6 \%)$ were males. Average age at presentation is $56.50 \pm 11.25$ years. 347 (68.8\%) had Hypertension, 258 (51.1\%) had DM, 370 (73.4\%) had Dyslipidemia and 104 (20.6\%) are smokers. $425(84.3 \%)$ presented with CSA and 79 (15.6\%) with ACS. $102(20.2 \%)$ patients had LV dysfunction. Of these 128 patients, $45(35.1 \%)$ had mild, $37(28.9 \%)$ had moderate and $46(35.9 \%)$ had severe LV dysfunction. Most of the patients presenting with ACS had some degree of LV dysfunction and most of the patients with moderate to severe LV dysfunction had TVD in CAG. Mean hemoglobin is $12.78 \pm 1.95 \mathrm{gm} / \mathrm{dl}$. Mean Total cholesterol is $147.16 \pm 93.7 \mathrm{mg} / \mathrm{dl}$, Triglycerides $133.88 \pm$ $61.60 \mathrm{mg} / \mathrm{dl}$, LDL $76.89 \pm 39.40 \mathrm{mg} / \mathrm{dl}$ and HDL $42.23 \pm$ $16.60 \mathrm{mg} / \mathrm{dl}$. A subgroup analysis is performed between males Vs females and diabetics Vs non-diabetics for mean lipid parameters. There is no significant difference is found among these groups in any of the individual lipid components. The occurrence of LV dysfunction is more in males $(30.8 \% \mathrm{Vs} 15.0 \% \mathrm{p}=0.000)$, females more commonly presented with CSA $(80.6 \%$ in males Vs $91.3 \%$ in females; $\mathrm{p}=0.00)$, and males with ACS $(19.3 \%$ in males Vs $8.6 \%$ in females).CAG was done in 393 $(77.9 \%)$ via radial route and in $111(22.1 \%)$ via femoral route. Again there is no significant difference between the male and female subgroups $(p=0.17)$.More number of catheters were required in males $(1.47 \pm 0.59$ Vs $1.25 \pm$ $0.47 ; \mathrm{p}=0.03$. The average amount of contrast used was $48.12 \pm 7.24 \mathrm{ml}$.

At least one of the epicardial coronaries showing $>70 \%$ stenosis was defined as abnormal CAG. In the total 504 patients undergoing CAG $303(60.1 \%)$ had abnormal CAGs. Of the patients having abnormal CAG, 148 $(48.8 \%)$ had single vessel disease (SVD), 85 (28\%) had double vessel disease (DVD), 70 (23.2\%) had triple vessel disease (TVD). Females had more incidence of normal coronaries in the coronary angiogram (33.8\% in males Vs 
$51.4 \%$ in females) $\mathrm{p}=0.00$, There is no significant difference between male and female subgroups in the occurrence of SVD, DVD or TVD.

We have subdivided the patients depending on having dyslipidemia or not, defined as having at least one of the following i.e. TC $>200 \mathrm{mg} / \mathrm{dl}, \mathrm{TG}>150 \mathrm{mg} / \mathrm{dl}, \mathrm{LDL}>130$ $\mathrm{mg} / \mathrm{dl}$ and HDL $<40 \mathrm{mg} / \mathrm{dl}$ in males, $50 \mathrm{mg} / \mathrm{dl}$ in females. According to this criteria, $370(73.4 \%)$ are qualified to be having dyslipidemia. We have compared the angiographic profile between these two subgroups. By using binary logistic regression we couldn't find in any difference of occurrence of normal CAGs $(\mathrm{p}=0.53)$, $\operatorname{SVD}(p=0.32), \operatorname{DVD}(p=0.78)$ and TVD $(p=0.88)$ between these subgroups.

We have divided the patients into two groups depending on having normal Vs abnormal CAG. Patients having abnormal CAG were again subdivided into SVD, DVD or TVD. We have compared these subgroups using multiple logistic regression for different baseline characteristics and risk factors including dyslipidemia and individual lipid components, tested for the significance. In patients presenting with severe CAD i.e. TVD there is a significant correlation between age $(p=0.01)$, male sex $(p=0.01)$, smoking $(p=0.02), \operatorname{HTN}(p=0.002), D M(p=$ $0.03)$, LV dysfunction $(p=0.006)$. Neither Dyslipidemia $(p=0.2)$ nor levels of Total cholesterol, HDL, LDL, TG determined the occurrence of TVD. Occurrence of DVD correlated significantly with age $(p=0.001)$ male gender $(p=0.002)$ and LV dysfunction $(p=0.02)$. In patients presenting with DVD also neither dyslipidemia ( $\mathrm{p}=$ 0.43 ) nor the individual lipid components had shown significant correlation. HTN $(\mathrm{p}=0.069)$ and DM $(\mathrm{p}=$ 0.074 ) have tendency for correlation with occurrence of DVD but not statistically significant. Male gender $(\mathrm{p}=$ $0.03), \operatorname{HTN}(p=0.01), \operatorname{LV}$ dysfunction $(p=0.00)$ are the primary determinants of occurrence of SVD. High levels of TG showed significant correlation with the occurrence of SVD with $p$ value of 0.03 . Occurrence of Dyslipidemia $(p=0.2)$ and other lipid component didn't show any correlation with the occurrence of SVD. Occurrence of dyslipidemia on a whole didn't show any significant correlation for the occurrence of any degree of CAD.

\section{CONCLUSION:}

In patients who are already on statins and presenting with CAD and found to be having abnormal CAG, primary determinants factors for the occurrence of CAD are age, male sex, HTN, DM and LV dysfunction of any severity but not dyslipidemia or the levels of TC, LDL, HDL or TG. Occurrence of dyslipidemia or levels of individual lipid component abnormalities except for high levels of TG in SVD didn't show any significant correlation with the occurrence of SVD, DVD or TVD.

\section{REFERENCES:}

1. Silverman MG, Ference BA, Im K, et al. Association between lowering LDL-C and Cardiovascular risk reduction among different therapeutic interventions: a systematic review and meta-analysis. JAMA 2016; 316: 1289-97. doi:10.1001/jama.2016.13985 pmid: 27673306.

2. Bibbins-Domingo K, Grossman DC, Curry SJ, et al. US Preventive Services Task Force. Statin use for the primary prevention of cardiovascular disease in adults: US Preventive Services Task Force recommendation statement. JAMA 2016; 316:1997-2007. doi:10. 1001/ jama.2016.15450 pmid: 27838723.

3. JBS3 Board. Joint British Societies' consensus recommendations for the prevention of cardiovascular disease (JBS3). Heart 2014;100 (Suppl 2):ii1-67. doi: 10. 1136 /heartjnl-2014- 305693 pmid:24667225.

4. National Institute for Health and Care Excellence. Cardiovascular disease: risk assessment and reduction, including lipid modification. https:// www. nice. org. uk/ Guidance/CG181. 2016.

5. Stone NJ, Robinson JG, Lichtenstein AH, et al. American College of Cardiology/American Heart Association Task Force on Practice Guidelines. 2013 ACC/AHA guideline on the treatment of blood cholesterol to reduce atherosclerotic cardiovascular risk in adults: a report of the American College of Cardiology/American Heart Association Task Force on Practice Guidelines. Circulation 2014;129 (Suppl 2):S1-45. doi:10.1161/01.cir.0000437738. 63853.7a pmid: 24222016.

6. Catapano AL, Graham I, De Backer G, et al. Authors/Task Force Members. 2016 ESC/EAS Guidelines for the management of dyslipidaemias: The Task Force for the Management of Dyslipidaemias of the European Society of Cardiology (ESC) and European 
Atherosclerosis Society (EAS) developed with the special contribution of the European Association for Cardiovascular Prevention \& Rehabilitation (EACPR). Atherosclerosis 2016;253:281-344. doi: 10.1016/ j. atherosclerosis.2016.08.018 pmid: 27594540.

7. Anderson TJ, Grégoire J, Pearson GJ, et al. 2016 Canadian Cardiovascular Society guidelines for the management of dyslipidemia for the prevention of cardiovascular disease in the adult. Can J Cardiol 2016;32:1263-82. doi:10.1016/j.cjca.2016.07.510 pmid: 27712954.

8. Dupuis J, Tardif JC, Cernacek P, Théroux P. Cholesterol reduction rapidly improves endothelial function after acute coronary syndromes. The RECIFE (reduction of cholesterol in ischemia and function of the endothelium) trial. Circulation 1999;99: 3227-33.

9. Ridker PM, Rifai N, Pfeffer MA, Sacks FM, Moye LA, Goldman $S$, et al. Inflammation, pravastatin, and the risk of coronary events after myocardial infarction in patients with average cholesterol levels. Cholesterol and Recurrent Events (CARE) Investigators. Circulation 1998;98:839-44.

10. Lefer DJ. Statins as potent anti inflammatory drugs. Circulation 2002;106:2041-2.

11. Ridker PM, Danielson E, Fonsec a FA, Genest J, Gotto AM Jr, Kastelein JJ, et al; JUPITER Study Group. Rosuvastatin to prevent vascular events in men and women with elevated C-reactive protein. N Engl J Med 2008;359:2195-207.

12. Lacoste L, Lam JY, Hung J, Letchacovski G, Solymoss CB, Waters D. Hyperlipidemia and coronary disease. Correction of the increased thrombogenic potential with cholesterol reduction. Circulation 1995; 92:3172-7.

13. MRC/BHF Heart Protection Study of cholesterol lowering with simvastatin in 20536 high-risk individuals: a randomized placebo-controlled trial. The Lancet. 2002 Jul 6;360(9326):7-22.

14. Sacks FM, Pfeffer MA, Moye LA, Rouleau JL, Rutherford JD, Cole TG, et al. The effect of pravastatin on coronary events after myocardial infarction in patients with average cholesterol levels. Cholesterol and Recurrent Events Trial investigators. N Engl J Med 1996;335:1001-9.

15. Prevention of cardiovascular events and death with pravastatin in patients with coronary heart disease and a broad range of initial cholesterol levels. The LongTerm Intervention with Pravastatin in Ischaemic Disease (LIPID) Study Group. N Engl J Med 1998;339:1349-57.

16. Cannon $\mathrm{CP}$, Braunwald E, McCabe $\mathrm{CH}$, Rader DJ, Rouleau JL, Belder $\mathrm{R}$, et al. Intensive versus moderate lipid lowering with statins after acute coronary syndromes. N Engl J Med. 2004 Apr 8;350(15):1495-504.

17. Waters DD, Guyton JR, Herrington DM, McGowan MP, Wenger NK, Shear C, et al. Treating to New Targets (TNT) Study: does lowering low-density lipoprotein cholesterol levels below currently recommended guidelines yield incremental clinical benefit? Am J Cardiol. 2004 Jan 15;93(2):154-8.

18. Pedersen TR, Faergeman O, Kastelein JJP, Olsson AG, Tikkanen MJ, Holme I, et al. High-dose atorvastatin vs usual-dose simvastatin for secondary prevention after myocardial infarction: the IDEAL study: a randomized controlled trial. JAMA. 2005 Nov 16;294(19):2437-45.

19. Kjekshus J, Apetrei E, Barrios V, Böhm M, Cleland JGF, Cornel JH, et al. Rosuvastatin in Older Patients with Systolic Heart Failure. N Engl J Med. 2007 Nov 29;357(22):2248-61.

20. Fellström BC, Jardine AG, Schmieder RE, Holdaas H, Bannister K, Beutler J, et al. Rosuvastatin and Cardiovascular Events in Patients Undergoing Hemodialysis. N Engl J Med. 2009 Apr 2;360(14):1395407.

21. Wanner C, Krane V, März W, Olschewski M, Mann JFE, Ruf G, et al. Atorvastatin in Patients with Type 2 Diabetes Mellitus Undergoing Hemodialysis. N Engl J Med. 2005 Jul 21;353(3):238-48.

22. Tavazzi L, Maggioni AP, Marchioli R, Barlera S, Franzosi MG, Latini $R$, et al. Effect of rosuvastatin in patients with chronic heart failure (the GISSI-HF trial): a 
randomized, double-blind, placebo-controlled trial. Lancet Lond Engl. 2008 Oct 4;372(9645):1231-9.

23. Colhoun HM, Betteridge DJ, Durrington PN, Hitman GA, Neil HAW, Livingstone SJ, et al. Primary prevention of cardiovascular disease with atorvastatin in type 2 diabetes in the Collaborative Atorvastatin Diabetes Study (CARDS): multicentre randomized placebo-controlled trial. Lancet Lond Engl. 2004 Aug 21; 364(9435):685-96.

24. Shepherd J, Cobbe SM, Ford I, Isles CG, Lorimer AR, Macfarlane PW, et al. Prevention of Coronary Heart Disease with Pravastatin in Men with Hypercholesterolemia. N Engl J Med. 1995 Nov 16; 333 (20):1301-8.

25. Nakamura H, Arakawa $\mathrm{K}$, Itakura H, Kitabatake A, Goto Y, Toyota T, et al. Primary prevention of cardiovascular disease with pravastatin in Japan (MEGA Study): a prospective randomized controlled trial. Lancet Lond Engl. 2006 Sep 30;368(9542):1155-63.

26. Downs JR, Clearfield M, Weis S, Whitney E, Shapiro DR, Beere PA, et al. Primary prevention of acute coronary events with lovastatin in men and women with average cholesterol levels: results of AFCAPS/TexCAPS. Air Force/Texas Coronary Atherosclerosis Prevention Study. JAMA. 1998 May 27;279(20):1615-22.

27. Ridker PM, Danielson E, Fonseca FAH, Genest J, Gotto AMJ, Kastelein JJP, et al. Rosuvastatin to Prevent Vascular Events in Men and Women with Elevated CReactive Protein. N Engl J Med. 2008 Nov 20; 359(21):2195-207.

28. Jukema JW, Bruschke AV, van Boven AJ, Reiber JH, Bal ET, Zwinderman AH, et al. Effects of lipid lowering by pravastatin on progression and regression of coronary artery disease in symptomatic men with normal to moderately elevated serum cholesterol levels. The Regression Growth Evaluation Statin Study (REGRESS). Circulation 1995;91: 2528-40.

29. Nissen SE, Tuzcu EM, Schoenhagen P, Brown BG, Ganz P, Vogel RA, et al; REVERSAL Investigators. Effect of intensive compared with moderate lipid-lowering therapy on progression of coronary atherosclerosis: a randomized controlled trial. JAMA 2004;291: 1071-80.

30. Okazaki S, Yokoyama T, Miyauchi K, Shimada K, Kurata T, Sato $\mathrm{H}$, et al. Early statin treatment in patients with acute coronary syndrome: demonstration of the beneficial effect on atherosclerotic lesions by serial volumetric intravascular ultrasound analysis during half a year after coronary event: the ESTABLISH Study. Circulation 2004;110: 1061-8.

31. Nissen SE, Yock P. Intravascular ultrasound: novel pathophysiological insights and current clinical applications. Circulation 2001; 103:604-16.

32. Ballantyne CM, Raichlen JS, Nicholls SJ, Erbel R, Tardif JC, Brener SJ, et al; ASTEROID Investigators. Effect of Rosuvastatin therapy on coronary artery stenoses assessed by quantitative coronary angiography: a study to evaluate the effect of Rosuvastatin on intravascular ultrasound-derived coronary atheroma burden. Circulation 2008;117:2458-66. 